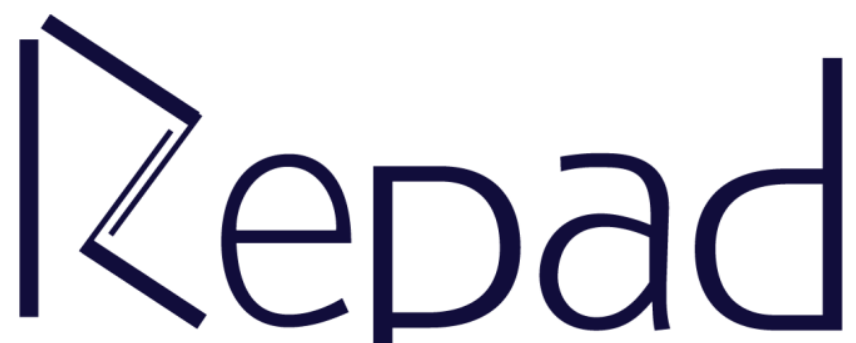

vol. 3, n. 3, Setembro-Dezembro/2019

Revista Estudos e

Pesquisas em Administração 


\title{
INNOVATION PROGRAMS MODELS: Design and management
}

\author{
Joaquin Jose Carvalho Proença \\ Universitat Politècnica de València, València, Spain \\ joaquinproenca@icloud.com \\ https://orcid.org/0000-0002-6423-6034
}

\begin{abstract}
Innovation projects might design, develop and implement a new practical and structured approach to create a managerial model for innovation. Small business management skills shortcomings (in economic, financial or human management), or resource limitations are not an innovation issue neither the sector or industry. It is a matter of lack of structured processes that integrate product, service, processes, marketing, and business models innovation, and at the same time create the capabilities that empower business leaders to act on innovation. Innovation programs practiced in a small business setting stressed or emphasized how to do it in two experiences in Peru and Colombia. Product and service innovation was based on methodologies on four axes; scanning the environment, immersion learning, gamification, lean and design thinking. While business model innovation based on the same processes and methodologies required additional capabilities and tools. That might involve innovation models framework, business models design tools, partnership value network, all focused on business context (trends and technologies), users as value co-creator, digital platforms, and ecosystems.
\end{abstract}

Keywords: Innovation Programs, Innovation processes, Product innovation, Service innovation, SMEs dynamic capabilities, Business Model Design, Strategic Processes.

\section{MODELOS DE PROGRAMAS DE INOVAÇÃO: Projeto e gerenciamento}

\section{Resumo}

Projetos de inovação podem desenhar, desenvolver e implementar uma abordagem prática e estruturada, com o objetivo de criar um modelo gerencial de inovação. As deficiencias nas habilidades de gerenciamento de pequenas empresas (na gestão econômica, financeira ou humana) ou as limitações de recursos não é uma questão de inovação nem do setor ou da indústria. É a falta de processos estruturados que integram inovação de produtos, serviços, processos, marketing e modelos de negócios e, ao mesmo tempo, criam os recursos que capacitam os líderes de negócios a agirem sobre inovação. Os programas de inovação praticados em pequenas empresas enfatizaram o como fazê-lo em duas experiências no Peru e na Colombia. A inovação de produtos e serviços foi baseada em metodologias em quatro eixos, contexto empresarial, aprendizado por imersão, gamificação, lean e design thinking. A inovação do modelo de negócios baseada nos mesmos processos e metodologias exije recursos e ferramentas adicionais, envolvendo estrutura de modelos de inovação, ferramentas de desenho de modelos de negócios, rede de valor de parceria, todos focados no contexto de negócios (tendências e tecnologias), usuários como co-criadores de valor, plataformas digitais e ecossistemas.

Palavras-chave: Programas de inovação, Processos de inovação, Inovação de produtos, Inovação de serviços, Capacidades dinâmicas para PMEs, Desenho de modelos de negócios, Processos estratégicos. 
Submetido: $15 / 10 / 2019$

Aceito: 21/11/2019

Introduction

Publicado: 31/12/2019

The innovation programs focused on the benefits for small businesses to adopt a strategy of open innovation and co-creation on innovation processes; how innovation processes can solve knowledge and key business challenges; and not less important creating capabilities that empower business leaders.

The research goal was to set up technical competences and test the program's performance for value creation at micro, small and medium businesses.

In that order were formulated seven hypotheses that went through a process of validation during the innovation programs to create value through new products, services, and business models design and redesign.

Although the limitations of financial resources and/or intellectual capital of small businesses limit the implementation of multi-function teams into project management, the creation of R\&D departments, a specific lab or innovation center, or knowledgeintensive business consultancy, there are innovative collaborative processes with partners that small companies can take advantage of.

Both programs in Perú and Colombia selected small, medium-sized businesses in the services sector and focused on the management of innovation capabilities for SMEs with limited human and financial resources. Stages, classifications, and types of methodologies (qualitative) used were based on a discretionary selection of low-cost tools for small businesses.

Multiple methods were used according to the stages of diagnosis (Coolhunting, Customer Journey Map, Netnography, Innovation Models Framework) learning (Ethnography, in-depth interviews, Projective techniques, Business Model Design), engagement (Group Dynamic Sessions with Gamification, Business Model Stress Test) and change (Design Thinking, Sprint).

\section{Literature Review}

Overview

Although the creation and product development have been associated with marketing, it is the literature review on innovation wherein the most interesting approaches for this research were found. Meanwhile, business models have no place in economic theory, they likewise lack an acceptable place in organizational and strategic studies, and in marketing science (Teece, 2010).

Firstly, there is innovation derived from the processes of co-creation with lead users; these are the people to first identify the need for a product or service, according to Von Hippel (1986). Subsequently, Prahalad and Ramaswamy (2000) define co-creation as users participating directly, and sometimes repeatedly, in the design, development of products, services, and innovation processes.

The ultimate competitive advantage of continuing business model innovation (Mitchell \& Coles, 2003) was a pioneer work that first explicitly discussed that businesses can purposefully innovate their business model.

In the same year two milestone concepts: Open Innovation (Chesbrough, 2003) strategy of knowledge flows with stakeholders, customers, suppliers, distributors, 
universities, nongovernmental organizations (NGOs), innovation centers and living labs to co-create unique value; Customer Development (Blank, 2003) as a process for startups, which shouldn't be categorized as smaller versions of large companies. Edward Freeman (1984) much earlier impulsed the idea of stakeholders, firms' view to increasing value for parties other than shareholders.

Service-Dominant Logic in which all economic activity is an exchange of services since the customer is always a co-creator of value and there is no value until an offering is used from Vargo and Lusch (2004). S-D logic is essentially a value-co-creation model that sees all actors as resource integrators, tied together in shared systems of exchange service ecosystems or markets (Vargo, 2011).

Brown (2008) methodology used in the consulting company IDEO (since 1991), highlighted the human approach to innovation consisting of empathy, definition, ideation, prototyping, and tests to deliver results financially interesting and technically feasible.

Teece (2010) conceptualized the business model as the design or architecture of the value creation, delivery, and capture mechanisms of the business, Osterwalder and Pigneur (2010) introduced a standard framework for business model canvases.

Ries (2011) refines Steve Blank's (2003) Customer Development methodology (established on Customer Discovery and Customer Validation) and initiates the Lean movement of building a minimum viable product as quickly as possible based on product iteration, testing business hypothesis and validated learning. Later Lean canvas was created by Maurya (2012).

Theory development by Vargo, Wieland, and Akaka (2015) mentioned that value is co-created through service ecosystems beyond business models resource integration.

The innovation theory framework used by small and medium businesses was accompanied by market evolution. Starting with the dot.com boom and bust of 19982001, emergent companies with zero or negative profits and low revenues advocated the idea that traditional revenue and profitability models no longer applied. With the bust and no easy access to funding, new low cost and agile processes were incorporated in innovation.

Driving factors for the surge of business model innovation field can be found in low-cost innovation processes, information and communication technologies (ICT), globalization besides 3D printing, social media, emerging knowledge economy, the Internet (including consumer power of comparison shopping, recommendations), new channels of distribution (e-commerce), technology 'cloud-based' computing models, the outsourcing and offshoring of many business activities, and the restructuring of the financial services industry (Teece, 2010).

Chesbrough and Rosenbloom (2002) signaled "increased mobility of workers, more capable universities, declining US hegemony, and growing access of startup firms to venture capital, changed the conditions under which firms innovate". These conditions allowed a broader range of stakeholders' innovative partnerships from the collaboration between organizations, (universities research and entrepreneurship programs, funding startups, labs, collaborating with distributors and suppliers), or organization and users, or even between business models.

Chesbrough and Bogers (2014) when updated open innovation definition turned the focus from inflows and outflows of knowledge that can be purposely managed by permeable organizations to a "distributed innovation process based on purposely managed knowledge flows across organizational boundaries, using pecuniary and nonpecuniary mechanisms in line with the organization's business model". 
The open innovation emphasis it wasn't only about value creation anymore, but how to capture value as well and that is a determinant for business model innovation. Innovation programs developed in Latin America were focused on processes and dynamic capabilities and capacities more than innovative typologies of business ventures.

In this standpoint, Open Innovation relates to commercialization models (of new or improved products, services, processes, business models), rather than solely development models. Further, these business model viewpoints often align with modern innovation entrepreneurship outlook and the start-up concept of a temporary organization designed to looking for a repeatable and scalable business model (Blank, 2013).

Wieland, Hartmann and Vargo (2017) point the absence in the literature of a "clear conceptualization of what business models are" (Chesbrough \& Rosenbloom, 2002; Zott, Amit \& Massa, 2011) "and, perhaps more importantly, what business models do" (Doganova \& Eyquem-Renault, 2009).

Although even if business model innovation is considered a source of value creation (more sustainable than product or service innovation) "the business model innovation (BMI) literature is mainly focused on either examining the facilitators of BMI as an organizational process or identifying new and "innovative" types of ventures" (Foss $\&$ Saebi, 2016). This study on business models peer-reviewed articles further mentions "in comparison with the volume of research on business models, the number of published papers that address BMI per se is still comparatively low" (Foss \& Saebi, 2016) even comparing with topics such as open innovation and dynamic capabilities.

This research stands on that business model is defined by how a company creates value for itself and its customers (Blank, 2013) and what business models do are value creation, value proposition and value capture (Baden-Fuller \& Mangematin, 2013).

According to Michel, Brown and Gallan (2008) what defines innovation is the modification of value as defined and used by the customer, not value in production and exchange. Value is created in conjunction with customers as a source of competitive advantage (Karpen, Bove \& Lukas, 2012).

Formulating hypothesis

Seven hypotheses were formulated in consideration of innovation programs in the scope of a practitioner approach of testing and validating processes for product, service, business model innovation as an opportunity for small business competitive advantage.

H1 Importance of industries and sectors versus owners/founders leadership and business innovation ADN for innovation programs.

$\mathrm{H} 2$ Similarity of processes and methodologies for products/services versus business models innovation.

H3 Holistic view of product/services/process/marketing/business models innovation for unique solutions according to businesses' vision, capabilities, and resources.

H4 Full processes departure from a unidirectional value flow from businesses to customers in value creation, delivery, and capture.

H5 Relevance assessment of the degree and innovation potential of the company before and after the program.

H6 Short duration of innovation programs conditions the entrepreneur's capabilities development and empowerment. 
H7 Balance of proactive innovation culture based on opportunist advantages in industry and outside it, technological changes, or reactive innovation based on problemsolution.

\section{Methodology}

Both programs in Perú and Colombia selected small, medium-sized businesses in the services sector and open innovation and co-creation strategy for the development of new products and services.

Program in Peru included businesses that were in accommodation (hotel Gold Infinity) and health (hospital Solidaridad) sectors. Meanwhile, the program in Colombia involved six businesses Summoled, Branding CO, Hommie, OKms, Cossio Porto Films, Next Audit in lighting design, marketing \& advertising, home cleaning services, car integral services platform, visual audio production, IT consulting industries.

In the innovation program in Peru, the methodologies and activities were applied and self-paced for each business. It was developed along six months with loose and minimal participation from business leaders.

The innovation program in Colombia was intensive consisting of weekly cocreation processes with businesses, with a shorter duration of ten weeks. Nearly twothirds of the project was dedicated to data collection (including internal diagnosis, context analysis, users observation, and interviews) while generation and validation of ideas occupied slightly over the last third part of the project.

Within an innovation program's new model design it was chosen users collaboration and innovation processes. For product, services and business model innovation were followed stages of diagnosis (context and innovation model framework); learning (immersion and business model redesign); engagement (ideation and business model stress test) and change (validation and sprint). See Figure 1.

Figure 1. Innovation Programs Stages Management

\begin{tabular}{|c|c|c|c|c|}
\hline & $\begin{array}{l}\text { ORGANIZATIONS } \\
\text { ADN }\end{array}$ & $\begin{array}{l}\text { USERS } \\
\text { COLLABORATION }\end{array}$ & $\begin{array}{l}\text { INNOVATION } \\
\text { PROCESSES }\end{array}$ & $\begin{array}{l}\text { GROWTH } \\
\text { HACKING }\end{array}$ \\
\hline Diagnosis & $\begin{array}{l}\text { Innovation } \\
\text { Mapping }\end{array}$ & Context & $\begin{array}{l}\text { Innovation Models } \\
\text { Framework }\end{array}$ & Landing Pages \\
\hline Learn & $\begin{array}{l}\text { Knowledge } \\
\text { Management }\end{array}$ & Inmersion & $\begin{array}{l}\text { Business Model } \\
\text { Redesign }\end{array}$ & Influencers \\
\hline Engage & Creativity & Ideation & $\begin{array}{l}\text { Business Model } \\
\text { Stress Test }\end{array}$ & Online Reputation \\
\hline Change & $\begin{array}{l}\text { Change } \\
\text { Management }\end{array}$ & Validation & Sprint & $\begin{array}{l}\text { Content } \\
\text { Management }\end{array}$ \\
\hline Deliver & Scenario Planning & & & \\
\hline
\end{tabular}

Source: Author (2019) 
Multiple qualitative and low-cost methodologies were used according to the stages.

Innovation project in Peru followed Customer Development (Blank, 2003) to understand how users interact with products and services in the context of use. Methodologies included customer discovery (examining the business environment, ethnography, in-depth interviews) and customer validation (group dynamics sessions).

The innovation project in Colombia included: a) context-related, Coolhunting (trends analysis), Customer Journey Map (critical incidents), Netnography (content analyses and reputation), Innovation Models Framework (Doblin, Xplan, Navigator); b) immersion related, Ethnography (participant observation), In-depth Interviews (latent needs exploration), Projective techniques (storytelling, role play, brand personification), Business Model Design (Business Model, Lean, Service Logic Canvas, STOF, VISOR, Partner Value Network); c) ideation related, group dynamic sessions (Gamification, Business Model Stress Test); change related (Design Thinking, Sprint).

\section{Methods for insights and absorptive capacity}

Projective techniques, Storytelling Role Play, Brand Personification

In the scope of qualitative research, businesses can use stories and anecdotes additionally to facts and statistics so that their target believes in something, are excited and inspired. The process begins to establish the goal of what the audience should know, think, feel, or do afterward they heard the story, according to if they are investors or customers. The value proposition canvas right side or a persona canvas might help define the audience.

A story within a context the users feel identified on shared values, experiences, leadership and action. A narrative with beginning, middle, end that describes an object, process, phenomenon, immerses the audience into the scene, have an A-HA moment with the main point of the story, and persuasive arguments for the audience to have favorable or change their opinion.

The role-play in socio drama allows to co-produce experiences and service situations that are not yet real. The simulation of a real environment or situation helps the participants to consider the possible consequences of their actions and the possible actions and future reactions of other participants (Bell, 2009).

Acting is an impromptu simulation of a situation that may represent a person's digital interaction or dialogue between people either to enact aspects of a service, testing an interaction to build and detail the steps for the service to unfold, and improve dynamic experiences. One group or just two people are selected to participate in the acting out.

It's necessary dialogue and that each participant allows himself to improvise and act as naturally as possible. Each one of the selected "actors" given a role (e.g. call center attendant filing a complaint with an unsatisfied customer) or a scenario using objects to delimit an experience so that there are actions and interactions between actors.

Service Prototype is a simulation of solution proposal, simulation of material artifacts, environments or relationships that represent one or more aspects of a service, to validate understanding at each point of contact. When prototyping creates context, people interact with the few physical elements designed, co-producing the experience in realtime. 
Projective techniques like brand personification are designed to encourage participants project their feelings and opinions towards other things (e.g. famous public characters, actors, influencers, politicians, or animals), to make it easier for them to reveal their deeper emotions and associations and thus reveal hidden aspects of the values of a brand or company.

\section{Methods to generate ideas}

Six Thinking Hats, Brainwriting

The Six Thinking Hats method (de Bono, 1985) allows that a thinker does one thing at a time not being outweighed by information, logic, emotions, and creativity. The white hat represents the factual, the yellow the positive things about the idea, the black hat the critical aspects, the red the emotional part and green the creative side. The blue one is about the process, planning, execution and control of other hats.

Brainwriting tool was created by Horst Geschka and colleagues, from Frankfurt Battelle-Institute, which emerged as method development for innovation management. Five participants sit around a table, each with a pencil and paper. The leader presents a problem to the group and writes the problem statement in a place visible to everyone.

The group discusses it to ensure that all participants understand it, then each person writes four ideas on a piece of paper, and then putting them face down in the center of the table to create a stockpile, participants take a paper out of the stack and add they own ideas.

Anytime, they can put the piece of paper they have been working on face down again, pick up another one, and add more ideas to the new sheet. Optionally a participant can start a new sheet of their notebook and promptly add it to the stack. After 20-30 minutes, the process is finished, and the idea sheets are collected for later evaluation.

\section{Methods to validate ideas and prototype proposals}

Gamification

Workshops were used Brainwriting besides innovation games such as Buy a Product and Service, Speed Boat, 20/20 and business model card game.

Speed Boat, while drawing a boat on a whiteboard the goal is to see how fast goes the boat. The boat has a few anchors, the boat is the system and the features that the users don't like are its anchors. Participants write what they are dissatisfied (pains) on a ranking card and place it under the boat as an anchor that gives a notion of how much faster the boat would go if that anchor were cut.

Buy a Feature, the game starts creating a list of potential features that are likely to be in product development and provide each with a price. Just like for any product, the price can be based on development costs, customer value, etc. Users choose the right set of features that they want using play money. The goal is to motivate negotiations between users as to which features are the most important.

20/20 Vision, as in an optometrist office when getting fitted the glasses this game helps users deciding which features are the highest priority. Starting by writing one feature each on ranking cards. After shuffling the pile and put them face down, it's taken the first one from the top of the pile and its put on the wall. In the next one, participants 
are asked if it is more or less important than the previous. If it is more important, its placed higher and if it is less important its placed lower giving a vision of what the market wants (Gray et al., 2010).

The business model card game is a set of 52 cards with three to five players that allows rethinking business model options that have already been used by others. An existing business or a new idea should be used as a starting point.

After being explained or visualized the selected business or idea, the cards are divided randomly between all players. Each participant has five minutes to choose three cards that are more suitable for the business. After the cards are put on the table and argued the reasons for the choices done, the ones with the most convincing arguments can then be elaborated upon (Business Makeover, 2017).

\section{Innovation models framework: Ten Types of Innovation, Navigator, 12 Business}

Innovation Dimensions, Visual Process Innovation

Ten types of innovation from left to right:

Profit Model, the way in which you make money.

Network, connections with others to create value.

Structure, alignment of your talent and assets.

Process, signature or superior methods to doing your work.

Product Development, distinguishing features and functionality.

Product System, complementary products and services.

Service, support and enhancements that surround your offerings.

Channel, how your offerings are delivered to customers and users.

Brand, representation of your offerings and business.

Customer Engagement, distinctive interactions you foster.

(Doblin, 2015).

The blocks on the left side of the framework are the most internally focused and on the right side, the blocks become increasingly focused on users.

Innovation failure might not have to do with a lack of creativity, but a lack of systematic and structured processes. Successful innovators use many types of innovation they don't focus on the only type of innovation (Doblin, 2015).

The St. Gallen business model Navigator design (initiation, ideation, integration) and implementation (trial and error test) are based on ecosystem analysis of players, change drivers, adaption to the fifty-five patterns identified and business model definition on what, who, why and how.

It highlights both ecosystem and testing approaches (not considered in Osterwalder business model canvas) within patterns which affects business models components on what is offered to the customer, how is the value proposition created, who is the target customer and how is revenue created (Gassmann, Frankenberger \& Csik, 2014).

Business innovation is achieved by creatively changing one or more dimensions of the business system. For that is necessary to think systemically in terms of all possible dimensions through which a firm can look for opportunities to innovate (Sawhney, Wolcott \& Arroniz, 2007). 
Innovation Radar is a tool that relates all of the company dimensions and could help determine how its current innovation strategy benchmark with competitors; in terms of offerings, platform, solutions, customers, customer experience, value capture, processes, organization, supply chain, presence, networking, brand.

Visual Process Innovation uses a framework and toolbox that follows five phases: Current State, includes visual mapping of the current state of an existing process or the starting point for creating a new or improved one; Future State, visually maps the new process from beginning to end includes ideation, prototyping, and visual mapping of the future state; Validate, through scenarios method and stress testing for improvement, either in controlled or live environments, before launching; Activate, adoption of a new process needs change management in what to believe, to know how to change and act differently; Embed, ensuring the process takes hold developing a culture and organizational structure that encourages and rewards people for identifying or implementing improvements, (Owens \& King, 2019).

\section{Business Model Design: Business Model, Lean and Service Logic Canvas. STOF, VISOR}

Further than using a business model either as a basis for enterprise classification or enterprise performance the methodology used was centered on the business model as a potential unit of innovation (Lambert \& Davidson, 2013). For the 10 week program of innovative processes (e.g. capabilities, competences, stages, milestones) were used both tools $\mathrm{s}$ from product and service innovation and specific tools related to the business model.

Criticism on Business Model Canvas (BMC) (Osterwalder, 2010) might be established on a) not valuing companies context either trends or technology; b) supports a unidirectional user customer proposition value questioned by theories that the user is always a co-creator of value. The user, besides being an external source of ideas in the process of trial-and-error of the development of new products and services, must be the facilitator of social and market acceptance through experience and perception, essential for the determination of value; c) might not be appropriate for digital businesses.

Some alternatives can complement BMC such as STOF (service, technology, organization, finance) and VISOR (vision, interface, service, organization, revenue) models.

Lean Canvas (Maurya, 2012) based on Osterwalder Business Model Canvas maintains nine blocks but introduces the problem block (top three problems users know they have), solution block (the possible solutions for the problems identified), unfair advantage block (something that can't be easily copied or bought that will have greater impact) and key metrics block (numbers to monitor progress). The other blocks were maintained (value proposition, channels, customer segments, cost structure, and revenue streams).

Service Logic Business Model Canvas advantage as it takes into account on each building block two perspectives: the service providers and the customer (Ojasalo \& Ojasalo, 2015). The canvas has its foundations on value formation in customers' viewpoints and daily routines concerning businesses with service design methodology, a process based on iteration with testing and learning and applied to each customer profile separately.

The first block is called the customer's world and desire for ideal value and is based on customer viewpoints and daily routines, reasons explicit and latent for buying. 
Value Proposition is the second block and it is about expectations. Third block Value Creation concerns the job to be done, customers reaching their goals. The fourth block focuses on the customer's interaction and co-production in the business activities and use of its resources. The fifth block called revenue streams and metrics analyses what the customer is willing to pay for the benefits includes branding as well. The sixth block Key Resources includes the intangible ones. The seventh block the Key Partners is related to value creation. The eight block include utilization and development of mobilizing resources and partners. Finally, the nine block cost structure and impact on customers value.

The following methods STOF and VISOR evaluate the viability of digital business model innovation that is more appropriate for partner, information and digital technologies business dependent.

STOF tool that focuses on trade-offs between (S) service, innovative service and product offered includes value proposition and branding; (T) Technology ICT needed for enabling innovation, includes internet platforms and applications, service quality, security and privacy issues; (O) Organization collaboration with partners, dependencies from core firm and key resources provided by network enterprises are critical for partnership design; (F) Finance balance of costs and revenues, sharing risks and investments based on costs or value.

On the other hand, VISOR tool that focuses on Vision (Value Proposition), how a specific segment is willing to buy a specific product or service and its context of use; (I) Interface, the user digital experience; (S) Service platform, in terms of technology and infrastructure; (O) Organization model, highlights the processes and relationships with the ecosystem; (R) Revenue model and revenue and costs with partners.

Partner Value

Businesses generally consist of alignment of multiple business models, which means when firms are willing to collaborate they may be looking for an opportunity not in the potential partner in general but within its specific business model.

Partnerships by definition are not a collaboration between companies, but rather a collaboration between business models within those companies (or two business models within the same company). A partnership is a value-creating entity, which leverages complementary values within two separate existing business models by connecting them. By combining value inputs from two business models, a partnership enables them to create new forms of value that they both benefit from (Doorneweert \& Vanhaverbeke, 2015).

Partnership canvas shows each partner's perspective on the partnership, how partners will connect values, and how the transfer of value will create the required value result. Value networks are established with actors, tangible and intangible mutual flows and transfers, what partners bring and what is in it for them in terms of resources, sales channels, money, and others.

This tool analyzes who the most important partners are. The value offer it what's present in the business model. The desired value is a quality that the partner would possess. Created value, what the business needs for its business model. Through transfer activities, these values are mutually (Doorneweert, Vanhaverbeke, 2015a). 


\section{Prototypes}

Prototypes are concepts that can be physical, virtual or storyboards as opposed to a minimum viable product (MVP) that has the attributes or benefits of the final product. The minimum viable product further than testing ideas test the basic capabilities that allow consumers to achieve the results they expect.

Sprint is a five-day process for test ideas and business questions through design and could be introduced before launching a minimal viable product. The process includes mapping the problem, sketch solutions based on inspiration and critical thinking, storyboard testable hypothesis (which is a step by step plan for prototyping), final prototype and test by observing how users react to the prototype.

Reiteratively key ingredients for successful projects are autonomy and quality time dedication from participants. Skills such as the ability to shape ideas, see patterns and adapt ideas; Speed to take decisions quickly and tested fast; Observation, talk and run business experiments with users; Prototyping from analogical, physical to more sophisticated digital (Osterwalder, 2018).

Market research is always insufficient, with variables that cannot be identified in their totality and are dependent on facilitators, actors and processes bias. Pivoting with a test, building prototypes, evaluation based metrics, might consolidate the whole process of learning based on facts.

\section{Results}

Stages, blocks, classifications were transversal in the businesses programs development in general and differences of both programs had to do with products and services innovation while business model innovation based on the same processes and methodologies required additional capabilities and tools.

Meanwhile, most of the business had a portfolio of ideas some already implemented they presented a lack of innovation processes (context/problem exploration/validation of innovative solutions), tools, value proposition definition, digital marketing strategy, efficient knowledge management from tacit to explicit (socializing, channels, periodic meetings, internal reports, internalization) and KPI's.

It wasn't so much a problem of management skills shortcomings, updated knowledge (attendance at workshops, conferences, events), short of ideas and initiatives it might be a matter of lack of structured processes.

The practitioner sessions had some common denominators, value proposition elaboration, identification and generating alliances, (the businesses, in general, followed a closed model of innovation), developing new products and services since there was a lack of knowledge of market needs (observation, interviews) and trends that business could exploit to diversify services and differentiate from the competition.

Incorporation of process automation in project management, channels, and relationships with clients and content management, were generally neglected.

\section{Discussion and future lines of research}

Other factors might be at work and are relevant to consider for these innovation processes to become effective or successful: Business leaders's skills (analytical, creative, self-criticism), business innovation ADN, diagnosis of the business-grade and innovation potential, innovation culture, creativity techniques, knowledge and change management, 
external cooperation with other resource-integrating partners and digital platforms as well.

In the same way, more studies are needed on open innovation within a network of partners and, above all, on the ecosystem or systemic activity of the actors and the competitiveness of small businesses. The complexity of creating value, not through technologies, business models, but institutional processes, ecosystems that give meaning to the proposed solutions to the market.

Technology might assure efficiency (digital platforms for services and marketplaces provides an exploration of underused resources), reduced costs, service quality, facilitate dynamic intelligence/absorptive capacity, crowdsourcing/eparticipation, prototyping/MVP capabilities. In which way and scope technology introduce businesses inference prediction on innovation processes is a field for research exploration.

Another future line of research the possible partnerships between start-ups and large companies to accelerate innovation. How bootcamps are more effective programs to develop radical products or services specifically related to the corporate that hosts these initiatives than consulting services, user-centric or internal innovation programs. Extrinsic benefits for Startups such as branding, suppliers contacts, sales, attracting financing might function as a higher stimulus for innovation.

\section{Conclusions}

H1 Industries and sectors are not relevant for innovation programs but owners/founders leadership and business innovation ADN is crucial.

Project management has goals of design, development and delivered although businesses needed change management to ensure the project's solutions are effectively embraced, adopted and used. Chesbrough (2010) have identified barriers to business model innovation, such as the cognitive inability of managers to understand the value potential of a new business model.

$\mathrm{H} 2$ Similarity of processes for products/services and business models innovation of experimentation, measure, and learning. Business model innovation requires specific tools.

Programs tend to stick to a strategy, conceptualizations without a design approach. Neglect of customer development processes of understanding unarticulated needs, motivations of users, prosumers, influencers and lead users without testing. Firms might be reluctant to implement innovation processes and taking advantage of partnerships and allies so don't generate and implement measures of an open strategy with stakeholders from the public, private and third sectors.

H3 Holistic view of product/services/business models innovation with processes and marketing innovation is necessary for innovation programs.

Program co-creation with businesses generates enough data but needs facilitators, flexible and adaptive teams and iterative sessions to adapt to each situation and bring value for the businesses.

H4 Full processes departure from a unidirectional value flow from businesses to customers in value creation, delivery, and capture.

Process innovation is necessary for the development of new services and business model redesign. Context research and immersion learning are necessary but not sufficient. 
However, dynamic group sessions including Gamification, Design Thinking and innovation framework models are conclusive for prototyping proposals and testing.

H5 Assessment relevance of the degree and innovation potential of the company before and after the program.

Might help identify areas to concentrate efforts to innovate (offer, platform, solutions, client, customer experience, value capture, process, organization, supply chain, presence, networks, brand) and barriers to be eliminated (well-defined strategic orientation for innovation, exploring new opportunities, iterative innovation processes, use of tools for innovation, innovation skills training, knowledge management, change management, incentive systems for innovation). Also, this final diagnosis incentive that solutions are adopted and used effectively by companies.

H6 Short duration of innovation programs conditions the entrepreneur's capabilities development and empowerment.

Vicious cycle with entrepreneurs unsatisfied with workshops, mentoring if they don't see practical and immediate results and the way around innovation programs need change framework, innovation culture to be effective.

H7 Businesses leaders as change actors, besides reactive innovation with an innovation program based on exploration, problem identification and finding solutions a culture of proactive innovation is much needed.

Businesses need capabilities to effectively adapt to the ever-changing context so individual, organizational and firm-level competencies, processes and behaviors are necessarily based on opportunist advantages to embrace market, industry and outside it, and technological changes more quickly and effectively.

Although the organizational design is necessary but not sufficient, it needs culture innovation and change management. Chesbrough (2010) have identified barriers to business model innovation, such as the configurations of assets and processes (which may be subject to inertia). Good past performance and longevity of the business model might undermine the capability of change and for that reason, emergent actors might take the lead in innovation.

\section{References}

Baden-Fuller, C., Mangematin, V. (2013) Business models: A challenging agenda. Strategic Organization, 11, 418-427.

Bell W. (2009). Foundations of futures studies. London, UK: Transactions Publishers.

Blank, S. (2003). The Four Steps to the Epiphany. Kindle book.

Blank, S. (2013). Why the lean start-up changes everything. Harvard Business Review May issue.

Brown, T. (2008). Design thinking. Harvard Business Review 86(6).

Business Makeover (2017). Business Model Cards. Retrieved from https://www.businessmakeover.eu/platform/envision/tool-detailed-

view id=f6a1edce7ea84edex-515e165ex1580afbbf8dx3880\&path=7fa6461219dafa32x4c675edbx 1582fd1b3adx-1008

Chesbrough, H., Rosenbloom, R. S. (2002). The role of the business model in capturing value from innovation: Evidence from Xerox Corporation's technology spin-off companies. Industrial and Corporate Change, 11(3), 529-555. 
Chesbrough, H. (2003). Open innovation: The new imperative for creating and profiting from technology. Harvard Business School Press.

Chesbrough, H. W. (2010). Business model innovation: Opportunities and barriers. Long Range Planning, 43(2-3), 354-363

Chesbrough, H., Bogers, M. (2014). Explicating open innovation clarifying an emerging paradigm for understanding innovation. Uncorrected proof, revises, August 05.

De Bono, E. (1985). Six Thinking Hats: An essential approach to business management. Little Brown \& Company.

Doblin (2015). Ten Types of Innovation. The building blocks of breakthroughs. Retrieved from https://doblin.com/dist/images/uploads/Doblin_TenTypesBrochure_Web.pdf

Doorneweert, B., Vanhaverbeke, W. (November 4, 2015). Business model design through partnerships. Retrieved from https://www.linkedin.com/pulse/business-model-designthrough-partnerships-bart-doorneweert/?trk=hp-feed-article-title-publish

Doorneweert, B., Vanhaverbeke, W. (December 7, 2015a). The partnership design process (understand, design, compare, evaluate). Retrieved from https://www.linkedin.com/pulse/partnership-design-process-understand-compare-bartdoorneweert/

Doganova, L., Eyquem-Renault, M. (2009) What do business models do?: Innovation devices in technology entrepreneurship. Research Policy, 38(10), 1559-1570.

Foss, N. J., Saebi, T. (2016). Fifteen years of research on business model innovation: How far have we come, and where should we go? Journal of Management, 43(1), 200-227.

Freeman, E. (1984). Strategic management: A stakeholder approach. Cambridge, New York: University Press.

Gassmann, O., Frankenberger, K., \& Csik, M. (2014). The Business Model Navigator. Financial Times Publishing International.

Gray, D., Brown, S., \& Macanufo, J. (2010). Gamestorming: A Playbook for innovators, rulebreakers and changemakers. Sebastopol, USA: O’Reilly Media.

Karpen, I. O., Bove, L. L., \& Lukas, B. A. (2012). Linking service-dominant logic and strategic business practice: a conceptual model of a service-dominant orientation. Journal of Service Research, 15(1), 21-38.

Lambert, S. C., Davidson, R. A. (2013). Applications of the business model in studies of enterprise success, innovation and classification: An analysis of empirical research from 1996 to 2010. European Management Journal, 31, 668-681.

Maurya, A. (2012). Running Lean. Iterate from Plan A to a Plan That Works. CA: O’Reilly Media Inc.

Mitchell, D., Coles, C. (2003). The ultimate competitive advantage of continuing business model innovation. Journal of Business Strategy, 24, 15-22.

Michel, S., Brown, S. W., \& Gallan, A. S. (2008). Service-logic innovations: how to innovate customers, not products. California Management Review, 50(3), 49-65.

Ojasalo, K., Ojasalo, J. (2015). Adapting business model thinking to service logic: An empirical study on developing a service design tool, IN J. Gummerus, K. von Koskull 
(Eds.), The Nordic School Service Marketing and Management for the Future (pp. 309333). Helsinki: Hanken.

Osterwalder, A., Pigneur, Y. (2010). Business model generation: A handbook for visionaries, game changers, and challengers. Hoboken: John Wiley \& Sons.

Osterwalder, A. (May 23, 2018). Strategyzer blog, https://blog.strategyzer.com/posts/2018/5/23/the-5-critical-success-factors-of-asuccessful-innovation-sprint

Owens, C., King, D. (2019). Visual Process Innovation ebook. Retrived from https://store.xplane.com/collections/tools/products/visual-process-innovation-ebook-1

Prahalad, C. K., Ramaswamy, V. (2000). Co-opting customer competence. HBR, Harvard Business Review, (January-February).

Ries, E. (2011). The lean startup. New York, USA: Crown Publishing Group.

Sawhney, M., Wolcott, R., \& Arroniz, I., (2007). The Twelve Different Ways for Companies to Innovate. IEEE Engineering Management Review, February 2007.

Teece, D. J. (2010). Business models, business strategy and innovation. Long Range Planning, 43, 172-194.

Vargo S., Lusch, R. (2004). Evolving to a new dominant logic for marketing. Journal of Marketing 68(1), 1-17

Vargo S. L. (2011). Market systems, stakeholders and value propositions. Toward a service-dominant logic-based theory of the market, IN Extending service-dominant logic. European Journal of Marketing, 45(1/2), 217-222.

Vargo, S. L., Wieland, H., \& Akaka, M. A. (2015). Innovation through institutionalization: A service ecosystems perspective. Industrial Marketing Management, 36(3), 309-312.

Von Hippel, E. (1986). Lead users: A source of novel product concepts. Management Science, 32(7), 791-805.

Wieland, H., Hartmann, N., \& Vargo, S., L. (2017). Business models as service strategy. Journal of the Academy of Marketing Science, 45, 925-943.

Zott, C., Amit, R., \& Massa, L. (2011). The business model: Recent developments and future research. Journal of Management, 37(4), 1019-1042. 